\title{
Association of body mass index with some fertility markers among male partners of infertile couples
}

This article was published in the following Dove Press journal:

International Journal of General Medicine

6 June 2013

Number of times this article has been viewed

\section{Masoumeh Hajshafiha' \\ Rasul Ghareaghaji ${ }^{2}$ \\ Sedigheh Salemi' \\ Nahid Sadegh-Asadi' \\ Homayoun Sadeghi- \\ Bazargani $i^{3,4}$}

'Kosar University Hospital, ${ }^{2}$ Faculty of Public Health Sciences, Urmia University of Medical Sciences, Urmia, Iran; ${ }^{3}$ Department of Statistics and Epidemiology, Tabriz University of Medical Sciences, Tabriz, Iran; ${ }^{4} \mathrm{WHO}$ Collaborating Center on Community Safety Promotion, Karolinska Institute, Stockholm, Sweden
Correspondence: Homayoun SadeghiBazargani

WHO Collaborating Center on Community Safety Promotion,

Department of Public Health Sciences, Division of Social Medicine, Karolinska Institute - 2nd floor, Norrbacka,

Stockholm 17। 76, Sweden

$\mathrm{Tel} / \mathrm{Fax}+46729218776$

Email homayoun.sadeghi@swedensp.se
Background: The available evidence on the role of obesity and body mass index (BMI) on male infertility has been controversial or inconclusive to some extent.

Objectives: The aim of this study was to investigate the role of BMI on some male-fertility laboratory indicators both among infertile and fertile men in an Iranian population.

Methods and materials: A total of 159 male patients who had lived as a partner in an infertile couple for at least 1 year, after regular reproductive activity in their married life, and who sought infertility consultation, were investigated. BMI was assessed, and a morning blood sample was taken assessing serum levels of testosterone, sex hormone-binding globulin, prolactin, luteinizing hormone (LH), follicle-stimulating hormone, and estradiol. Semen-analysis parameters were also measured.

Results: In this study, it was found that the likelihood of oligospermia was increased at higher BMI values. Obese men were found to be 3.5 times more likely to have oligospermia than those with normal BMI. BMI was not found to be associated with mean numeric values of the semen-analysis parameters, including sperm count, sperm morphology, and sperm motility. BMI was not significantly correlated with some hormone levels, such as LH, prolactin, and LH/follicle-stimulating hormone ratio. However, a statistically significant association was observed between BMI and estradiol $(P<0.01)$, sex hormone-binding globulin $(P<0.001)$, and also the testosterone/estradiol ratio $(P<0.001)$. A different pattern of associations in this study was observed when the associations between BMI and sexual hormone levels were compared between fertile and subfertile/infertile men.

Conclusion: The association explored between BMI and some sexual hormones and semen characteristics, as well as different patterns of this association between fertile and subfertile/ infertile men, will be of help to broaden our understanding of the effect of obesity on some male reproductive physiologic characteristics among fertile and infertile men.

Keywords: male infertility, body mass index, sperm analysis, sexual hormones

\section{Introduction}

The failure of a couple to conceive a pregnancy after trying to do so for at least 1 full year is defined as infertility. It is defined by World Health Organization as the failure to conceive following 12 months of unprotected intercourse. ${ }^{1,2}$ Global estimates of infertility range between $8 \%$ and $12 \%$ of couples with women of childbearing age, affecting 50-80 million people. Infertility has a high worldwide psychosocial burden, some aspects of it carrying higher importance in Eastern countries. ${ }^{3,4}$ Male infertility has a substantial share of the total infertility burden. ${ }^{5-7}$ There are many reasons why a man can be the one experiencing fertility issues, such as low sperm motility. There have been some studies in recent years pointing to an increased risk 
of abnormal semen parameters among overweight men, and a higher likelihood of subfertility among couples in whom the husband is obese. ${ }^{8}$

Adult obesity rate is increased by age and its prevalence have been increasing over the recent decades. ${ }^{9}$ It has turned into a major source of growing concern about obesity worldwide. ${ }^{10}$ This calls for greater clinical awareness of the effects of obesity on fertility and the need for improving our understanding of the underlying mechanisms, and finding appropriate interventions. ${ }^{8}$ The available evidence on the role of obesity and body mass index (BMI) on male infertility has been controversial or inconclusive to some extent. The aim of this study was to investigate the role of BMI on some malefertility laboratory indicators both among infertile and fertile men in an Iranian population.

\section{Materials and methods}

The study population consisted of men referred to Kosar Infertility Center in Urmia, Iran who were male partners of infertile couples seeking infertility treatment. Kosar Infertility Center is the sole referral infertility center in West Azerbaijan province of Iran. The inclusion criteria were being a male partner of an infertile couple at least for 1 year, having regular intercourse, and seeking infertility treatment at Kosar Infertility Center over the study period. The exclusion criteria were having diabetes, smoking, azospermia, and those who received drugs affecting semen parameters or sexual hormone levels. Through consecutive sampling, 180 subjects were screened over 4 months, 21 of whom were excluded due to exclusion criteria as described above, mostly due to azospermia and smoking. The remaining 159 male patients were investigated. Standard and calibrated tools were used to do the measurements. Height was measured with participants standing without shoes, using a standard metal ruler. Weight was measured while light clothes were worn. BMI was calculated dividing weight in kilograms by squared height in meters $\left(\mathrm{kg} / \mathrm{m}^{2}\right)$. To analyze the data, the BMI was categorized as $<20.0 \mathrm{~kg} / \mathrm{m}^{2}$ labeled as underweight, $20.0-25.0 \mathrm{~kg} / \mathrm{m}^{2}$ labeled as normal weight, $25.1-30.0 \mathrm{~kg} / \mathrm{m}^{2}$ labeled as overweight, and $>30.0 \mathrm{~kg} / \mathrm{m}^{2}$ labeled as obese. This BMI classification has been suggested for reproductive endocrinology research. ${ }^{11}$

A morning blood sample was obtained of $5 \mathrm{~mL}$ volume and sent to an authorized laboratory to assess serum levels of testosterone, sex hormone-binding globulin (SHBG), prolactin (PRL), luteinizing hormone (LH), follicle-stimulating hormone (FSH), and estradiol (EST). Semen samples were also taken from the participants at the hospital. In the few cases where the sample was taken out of the hospital, care was taken to securely transfer the samples in less than 30 minutes. In the case of problematic semen-analysis parameters, such as sperm concentration $<20 \times 10^{6} / \mathrm{mL}$, sperm motility less than $50 \%$, or normal sperm morphology $<30 \%$, the sample was repeated after 1 month before the subject could be included in the study. The second sample was used for analysis in such cases. The semen-analysis classification was done based on Fritz and Speroff. ${ }^{11}$ Data were analyzed using SPSS (IBM, Armonk, NY, USA) version 16 statistical software. Mean serum sex-hormone levels of FSH (mIu/mL), LH (mIu/mL), EST $(\mathrm{Pg} / \mathrm{mL})$, PRL $(\mathrm{mIu} / \mathrm{mL})$, SHBG $(\mathrm{Nmol} / \mathrm{L})$, and testosterone $(\mathrm{Ng} / \mathrm{mL})$, as well as $\mathrm{LH} / \mathrm{FSH}$ and testosterone (TES)/EST ratios were compared over the BMI groups using one-way analysis of variance. Post hoc pair-wise comparisons were also performed. Semen-analysis parameters were also compared in the same way. To assess the correlation between normally distributed numeric scales, the Pearson correlation coefficient was calculated. All the statistical tests were done on a two-tailed basis, and a $P$-value $<0.05$ was considered a statistically significant result.

The study was approved by the medical ethics committee of Urmia University. Informed consent was obtained from all the study participants.

\section{Results}

Based on the analysis of the semen parameters, 85 (53.5\%) were classified as fertile and $74(46.5 \%)$ were considered infertile males. Distribution of male infertility over the BMI groups is given in Table 1. Figure 1 presents the distribution of semen parameters over the BMI groups among infertile men.

In this study, it was found that the likelihood of oligospermia was increased at higher BMI values. Obese men were found to be 3.5 times more likely to have oligospermia than those with normal BMI. The figure was threefold for overweight men when compared with normal-BMI men.

BMI was not found to be associated with mean numeric values of the semen-analysis parameters, including sperm

Table I Distribution of male infertility frequency over the BMI groups, Kosar Infertility Center, Iran

\begin{tabular}{llll}
\hline BMI range & Fertile men & Infertile men & Total \\
\hline $\mathrm{BMI} \leq 20$ & $2(25 \%)$ & $6(75 \%)$ & $8(100 \%)$ \\
$20<\mathrm{BMI} \leq 25$ & $39(59.1 \%)$ & $27(40.9 \%)$ & $66(100 \%)$ \\
$25<\mathrm{BMI} \leq 30$ & $33(50 \%)$ & $33(50 \%)$ & $66(100 \%)$ \\
$\mathrm{BMI}>30$ & $\mathrm{II}(58 \%)$ & $8(42 \%)$ & $19(100 \%)$ \\
Total & $85(53.5 \%)$ & $74(54.5 \%)$ & $159(100 \%)$ \\
\hline
\end{tabular}

Abbreviation: BMI, body mass index. 


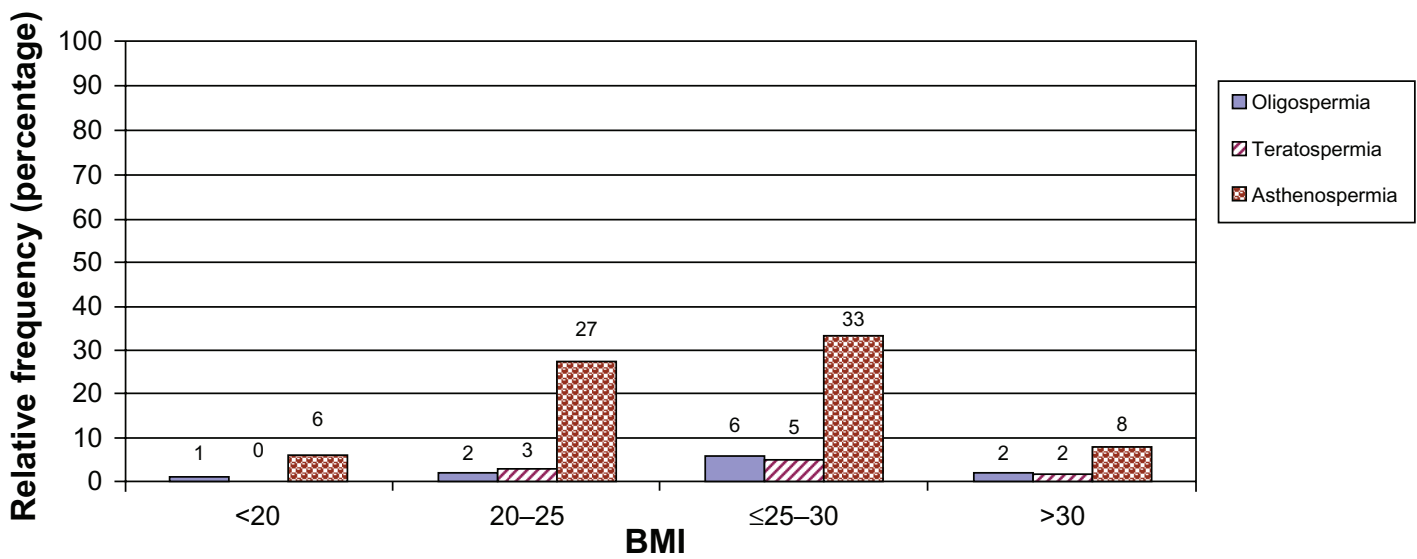

Figure I Distribution of the semen parameters over the BMI groups among infertile men.

Abbreviation: BMI, body mass index.

count, sperm morphology, and sperm motility. BMI was not significantly correlated with some hormone levels, such as LH, PRL, and LH/FSH ratio. Nevertheless, a statistically significant association was observed between BMI and EST $(P<0.01)$, SHBG $(P<0.001)$, and also the TES/EST ratio $(P<0.001)$. Details of comparisons are given in Table 2 .

The association of BMI with semen-analysis parameters and sex-hormone levels was also assessed separately for fertile and infertile males. The results showed that among fertile males, BMI was inversely correlated with TES levels $(r=-0.4, P<0.05)$. BMI was also inversely correlated with the TES/EST ratio $(r=-0.27, P<0.05)$. A reverse correlation was observed between BMI and SHBG ( $r=-0.35, P<0.001)$. No other significant correlation was explored between BMI and other sex hormone levels, such as LH, EST, FSH, LH/FSH, and PRL.

Among the infertile men, however, there were statistically significant correlations between BMI and measures like LH

Table 2 Semen-analysis parameters and sexual hormone levels compared for males over BMl groups

\begin{tabular}{|c|c|c|c|c|c|c|}
\hline \multirow[t]{2}{*}{ Parameter } & \multirow[t]{2}{*}{ Statistics } & \multicolumn{4}{|c|}{ BMI groups } & \multirow{2}{*}{$\begin{array}{l}P \text {-value } \\
\text { ANOVA }\end{array}$} \\
\hline & & $\begin{array}{l}<\mathbf{2 0} \\
\mathbf{n}=\mathbf{8}\end{array}$ & $\begin{array}{l}\mathbf{2 5}<\mathbf{B M I} \leq 30 \\
\mathbf{n}=\mathbf{6 6}\end{array}$ & $\begin{array}{l}\mathbf{2 5}<\text { BMI } \leq 30 \\
\mathbf{n}=\mathbf{6 6}\end{array}$ & $\begin{array}{l}>30 \\
n=19\end{array}$ & \\
\hline Count & Mean & 119.37 & 115.84 & 116.3 & 115.36 & NS \\
\hline $\mathrm{Mil} / \mathrm{mL}$ & SD & 76.8 & 65.1 & 71.6 & 74.8 & \\
\hline \multirow[t]{2}{*}{ Morphology } & Mean & 57.5 & 58.63 & 55.25 & 54.21 & NS \\
\hline & SD & 8 & 12.7 & 17.3 & 17.5 & \\
\hline \multirow[t]{2}{*}{ Motility } & Mean & 45.25 & 47.56 & 41.78 & 46.52 & NS \\
\hline & SD & 21.8 & 18.2 & 19.6 & 18.7 & \\
\hline \multirow[t]{2}{*}{ LH } & Mean & 4.17 & 4.21 & 3.71 & 3.92 & NS \\
\hline & SD & 3.2 & 2.2 & 1.9 & 2 & \\
\hline \multirow[t]{2}{*}{$\mathrm{FSH}$} & Mean & 6.87 & 5.47 & 4.97 & 5.75 & NS \\
\hline & SD & 6.78 & 3.38 & $3.6 \mathrm{I}$ & 3.83 & \\
\hline \multirow[t]{2}{*}{ PRL } & Mean & 276.97 & 238.49 & 241.26 & 282.44 & NS \\
\hline & SD & 79.1 & 139.2 & 150.3 & 205.3 & \\
\hline \multirow[t]{2}{*}{ LH/FSH } & Mean & 0.81 & 0.9 & 0.88 & 0.81 & NS \\
\hline & SD & 0.61 & 0.52 & 0.47 & 0.51 & \\
\hline \multirow[t]{2}{*}{ Estradiol } & Mean & 84.82 & 54.95 & 59.20 & 55.02 & 0.01 \\
\hline & SD & 31.1 & 23 & 22.9 & 25.3 & \\
\hline \multirow[t]{2}{*}{ Testosterone } & Mean & 5.59 & 4.85 & 3.78 & 3.14 & $<0.001$ \\
\hline & SD & 1.5 & 1.9 & 1.6 & 1.3 & \\
\hline \multirow[t]{2}{*}{ SHBG } & Mean & 54.76 & 31.52 & 23.54 & 18.65 & $<0.001$ \\
\hline & SD & 15.4 & 14.6 & 17.4 & 11.4 & \\
\hline \multirow[t]{2}{*}{ TES/EST } & Mean & 0.078 & 0.1 & 0.071 & 0.065 & $<0.001$ \\
\hline & SD & 0.046 & 0.049 & 0.035 & 0.034 & \\
\hline
\end{tabular}

Abbreviations: BMI, body mass index; LH, luteinizing hormone; FSH, follicle stimulating hormone; PRL, prolactin; SHBG, sex hormone-binding globulin; TES, testosterone; EST, estradiol; SD, standard deviation; ANOVA, analysis of variance; (MiL), Millions per (mL) milliliter; NS, not significant. 
$(r=-0.24, P<0.05)$, SHBG $(r=-0.44, P<0.001)$, and TES/EST ( $r=0.28, P<0.05$ ). No other significant correlation was observed between BMI and other sex-hormone levels, such as FSH, EST, LH/FSH, and PRL. Similarly, no statistically significant association was found between BMI and any of the semen-analysis parameters. Mean BMI was not found to be significantly different between the fertile and infertile men.

\section{Discussion}

Assessing the decreasing time-related trend in semen parameters goes in parallel with the increment in prevalence of obesity. ${ }^{12}$ Obesity may be associated with many health-related problems. Increased weight may coincide with conditions like diabetes, hypertension, and sex-hormonal status, which is well documented with respect to female studies.

In the present study, the authors investigated the association between BMI and serum concentrations of sex hormones as well as semen-analysis parameters. It was found that serum levels of some sex hormones among men varied based on BMI status. This was generally consistent with some previous studies in different settings. On the other hand, there have been studies reporting lack of significant correlation between BMI and any of the semen and hormonal parameters. ${ }^{13-16}$ Several studies have also indicated the existence of such an association. This includes both case reports of uncommon conditions and clinical research studies. ${ }^{17,18}$ In a Nigerian study on 120 men, researchers found statistically significant associations between BMI and serum levels of progesterone and EST, but these were not associated with PRL, TES, or LH serum concentrations. ${ }^{19}$

The present study found that the likelihood of oligospermia was increased at higher BMI values. Obese men were found to be 3.5 times more likely to have oligospermia than those with normal BMI. This was just slightly higher than the likelihood of having oligospermia among overweight men, which was three times more than normal-BMI men. This may indicate that being overweight is not much different than obesity in increasing the risk of oligospermia, and anyone out of normal BMI range should be worried. When comparing mean values, statistically significant association was not explored, but the increasing trend was promising towards an existing association if examined with a larger sample. This was in line with some previous studies, but at the same time the available evidence is not indicative of a strong association between BMI and sperm count. ${ }^{20}$ However, in one study, BMI has been found to be correlated only with sperm count, and sperm motility was not found to be associated with BMI. ${ }^{19}$ Nguyen et al found that when BMI was categorized into eight orders, a trend of increased infertility could be explored with increased BMI. Nevertheless, they considered a role for lower coital frequency rather than sexual dysfunction affecting the fertility in heavier men. ${ }^{21}$

The possible effect of BMI on male reproduction has also been studied on infertility management. It has been shown that overweight men have poorer outcome through the course of testicular sperm extraction. When it comes to severe obesity, the situation may be much worse, and some may not even be able to contribute to any pregnancies, despite successful sperm retrieval. ${ }^{22}$ Regarding the plausibility of the findings, some mechanisms may explain the effect of increased BMI on infertility among males. Some of these mechanisms include sleep apnea, changes in hormonal levels, and higher scrotal temperature in obese men, which in turn may give rise to impaired semen parameters. ${ }^{8}$

With respect to the existing controversy, one interesting study was published in 2011 that was conducted following obese men who lost weight. The authors found that weight loss may improve semen quality. ${ }^{23}$ Nevertheless, it is hard to say that in this particular study the improvement in semen quality was a result of the reduction in BMI or improved lifestyles, which may have affected the semen quality independent of weight loss.

Sperm DNA fragmentation studies have also found that sperm with high DNA damage exist more frequently in obese men than in normal-weight men, although the authors of such a study have concluded that only extreme levels of obesity may negatively influence male reproductive potential. ${ }^{24}$

A different pattern of associations in this study was observed when the associations between BMI and sexual hormone levels were compared between fertile and subfertile-infertile men. Several studies have documented a negative effect of obesity on semen quality both in normal fertile ${ }^{13,14}$ and subfertile-infertile males. ${ }^{21,25}$ It seems the time has come to get more focused also on the plausibility of such findings. Okada et al have shown that JHDM2A has a role in spermatogenesis and affects regulation of fat metabolic gene expression in some tissues, such as muscle tissue and brownfat tissue, and mice models confirmed the existence of obesity and hyperlipidemia. ${ }^{26}$ Other characteristics noted in male obesity that may cause an increased risk for infertility may be changes in retention and metabolism of environmental toxins, factors related to lifestyle. ${ }^{27}$

In conclusion, the association explored between BMI and some sexual hormones and semen characteristics, as well 
as different patterns of this association between fertile and infertile men, will be of help to broaden our understanding of the effect of obesity on some male reproductive physiologic characteristics. However, considering the available information in order to clarify the existing facts, it is recommended for future studies to consider assessing the role of weight loss on improving male fertility status through prospective cohort or interventional studies.

\section{Disclosure}

The authors report no conflicts of interest in this work.

\section{References}

1. Cooper TG, Noonan E, von Eckardstein S, Auger J, et al. World Health Organization reference values for human semen characteristics. Human reproduction update. 2010;16(3):231-245.

2. de Melo-Martin I. On cloning human beings. Bioethics. 2002;16: 246-265

3. Schmidt L. Psychosocial burden of infertility and assisted reproduction. Lancet. 2006;367:379-380.

4. Whiteford LM, Gonzalez L. Stigma: the hidden burden of infertility. Soc Sci Med. 1995;40:27-36.

5. Tekatli H, Schouten N, van DT, Burgmans I, Smakman N. Mechanism, assessment, and incidence of male infertility after inguinal hernia surgery: a review of the preclinical and clinical literature. Am J Surg. 2012;204:503-509.

6. Mackenna A. Contribution of the male factor to unexplained infertility: a review. Int J Androl. 1995;18 Suppl 1:58-61.

7. Mbizvo MT, Danso AP. Male reproductive function: a review on sperm fertilising ability and infertility. Cent Afr J Med. 1991;37:40-47.

8. Du Plessis SS, Cabler S, McAlister DA, Sabanegh E, Agarwal A. The effect of obesity on sperm disorders and male infertility. Nat Rev Urol. 2010;7:153-161.

9. Heráček J, Sobotka V, Urban M. Obezita a mužská neplodnost. [Obesity and male infertility.] Ceska Gynekol. 2012;77:450-456. Czech.

10. Low S, Chin MC, Deurenberg-Yap M. Review on epidemic of obesity. Ann Acad Med Singapore. 2009;38:57-59.

11. Fritz M, Speroff L. Clinical Gynecologic Endocrinology and Infertility, 8th ed. Philadelphia: Lippincott Williams \& Wilkins; 2010.

12. Hammoud AO, Meikle AW, Reis LO, Gibson M, Peterson CM, Carrell DT. Obesity and male infertility: a practical approach. Semin Reprod Med. 2012;30:486-495.
13. Stewart TM, Liu DY, Garrett C, Jorgensen N, Brown EH, Baker HW. Associations between andrological measures, hormones and semen quality in fertile Australian men: inverse relationship between obesity and sperm output. Hum Reprod. 2009;24:1561-1568.

14. Koloszár S, Daru J, Kereszturi A, Závaczki Z, Szöllosi J, Pál A. Effect of female body weight on efficiency of donor AI. Arch Androl. 2002; 48:323-327.

15. Eskandar M, Al-Asmari M, Babu CS, et al. Impact of male obesity on semen quality and serum sex hormones. Adv Urol. 2012;2012: 407601 .

16. Rybar R, Kopecka V, Prinosilova P, Markova P, Rubes J. Male obesity and age in relationship to semen parameters and sperm chromatin integrity. Andrologia. 2011;43:286-291.

17. Roth MY, Amory JK, Page ST. Treatment of male infertility secondary to morbid obesity. Nat Clin Pract Endocrinol Metab. 2008;4:415-419.

18. di Frega AS, Dale B, Di ML, Wilding M. Secondary male factor infertility after Roux-en-Y gastric bypass for morbid obesity: case report. Hum Reprod. 2005;20:997-998.

19. Egwurugwu JN, Nwafor A, Chike CP, et al. The relationship between body mass index, semen and sex hormones in adult male. Niger $J$ Physiol Sci. 2011;26:29-34.

20. MacDonald AA, Herbison GP, Showell M, Farquhar CM. The impact of body mass index on semen parameters and reproductive hormones in human males: a systematic review with meta-analysis. Hum Reprod Update. 2010;16:293-311.

21. Nguyen RH, Wilcox AJ, Skjaerven R, Baird DD. Men's body mass index and infertility. Hum Reprod. 2007;22:2488-2493.

22. Ramasamy R, Bryson C, Reifsnyder JE, Neri Q, Palermo GD, Schlegel PN. Overweight men with nonobstructive azoospermia have worse pregnancy outcomes after microdissection testicular sperm extraction. Fertil Steril. 2013;99:372-376.

23. Håkonsen LB, Thulstrup AM, Aggerholm AS, et al. Does weight loss improve semen quality and reproductive hormones? Results from a cohort of severely obese men. Reprod Health. 2011;8:24.

24. Chavarro JE, Toth TL, Wright DL, Meeker JD, Hauser R. Body mass index in relation to semen quality, sperm DNA integrity, and serum reproductive hormone levels among men attending an infertility clinic. Fertil Steril. 2010;93:2222-2231.

25. Hammoud AO, Wilde N, Gibson M, Parks A, Carrell DT, Meikle AW. Male obesity and alteration in sperm parameters. Fertil Steril. 2008;90: 2222-2225.

26. Okada Y, Tateishi K, Zhang Y. Histone demethylase JHDM2A is involved in male infertility and obesity. J Androl. 2010;31:75-78.

27. Hammoud AO, Gibson M, Peterson CM, Meikle AW, Carrell DT. Impact of male obesity on infertility: a critical review of the current literature. Fertil Steril. 2008;90:897-904.
International Journal of General Medicine

\section{Publish your work in this journal}

The International Journal of General Medicine is an international, peer-reviewed open-access journal that focuses on general and internal medicine, pathogenesis, epidemiology, diagnosis, monitoring and treatment protocols. The journal is characterized by the rapid reporting of reviews, original research and clinical studies across all disease areas.

\section{Dovepress}

A key focus is the elucidation of disease processes and management protocols resulting in improved outcomes for the patient.The manuscript management system is completely online and includes a very quick and fair peer-review system. Visit http://www.dovepress.com/ testimonials.php to read real quotes from published authors. 